Gut, 1988, 29, 161-166

\title{
Functional relationships between cricopharyngeal sphincter and oesophageal body in response to graded intraluminal distension
}

\author{
N A ANDREOLLO, D G THOMPSON, G P N KENDALL, \\ AND R J EARLAM \\ From the Departments of Gastroenterology and Surgery, The London Hospital, Whitechapel, London
}

SUMMARY Responses of the cricopharyngeal sphincter to graded intraluminal distension were studied in order to determine its response threshold and to define the functional relationship between the sphincter and oesophageal body. Nine normal subjects underwent manometric study using a multilumen tube with an attached inflatable balloon sited $10 \mathrm{~cm}$ below the sphincter. Sphincteric and oesophageal motor responses to six graded balloon inflations were recorded in each subject. The sphincter responded to distension with increasing rise in pressure, from a median value of $42.5 \mathrm{mmHg}$ at lowest levels of distension to $95 \mathrm{mmHg}$ at maximal tolerated distension. Non-swallow related contractile activity was stimulated in the oesophageal body proximal to the distension and increased in quantity as inflation progressed. Distal propagation of this secondary activity was progressively inhibited with increasing distension. These interrelated changes thus show the normal upper oesophageal clearance responses to intraluminal distension. It is suggested that their more widespread application, in addition to standard manometric techniques, might provide a more rational evaluation of those patients suspected to have impaired oesophageal clearance, but in whom standard manometry is non-diagnostic.

The cricopharyngeal (upper oesophageal) sphincter, situated at the intersection of the airway and the first part of the alimentary tract ${ }^{1}$ is formed mainly by the cricopharyngeal muscle, with additional fibres from the circular muscle of the oesophagus distally and the inferior pharyngeal constrictor proximally. ${ }^{23}$

The coordinated relaxation and contraction of this sphincter constitutes an integral part of normal deglutition, ensuring the passage of a bolus from the pharynx into the oesophagus, and additionally forms a dynamic barrier to prevent oesophagopharyngeal reflux and spillover into the tracheobronchial tree. This latter function is of particular importance because breakdown of this mechanism may be related to oesophagopharyngeal regurgitation and aspiration pneumonitis. ${ }^{134}$

Measurements of the resting sphincter pressure and its relationships to the oesophageal body have previously been attempted, ${ }^{\text {s-9 }}$ but the data are incom-

Address for correspondence: Dr D G Thompson, Department of Medicine, Hope Hospital, Salford M6 8HD.

Received for publication 7 August 1987. plete and often contradictory. Some groups, ${ }^{568}$ have observed an increase in pressure during intraluminal distension, others in contrast $^{7}$ have reported relaxation.

Preliminary studies ${ }^{10}$ of normal human oesophageal responses to experimental distension in our laboratory have shown that increased secondary peristalsis results. This response was abnormal in some patients with non-organic dysphagia who showed delayed isotope transit despite normal standard manometry. In this study a more systematic investigation of the responses of the upper oesophageal sphincter and body to graded distension was made in order to define the normal pattern more fully and to enable more accurate recognition of disordered function in non-organic dysphagia to be made in the future.

\section{Methods}

SUBJECTS

Nine healthy volunteers (eight men, one woman, 


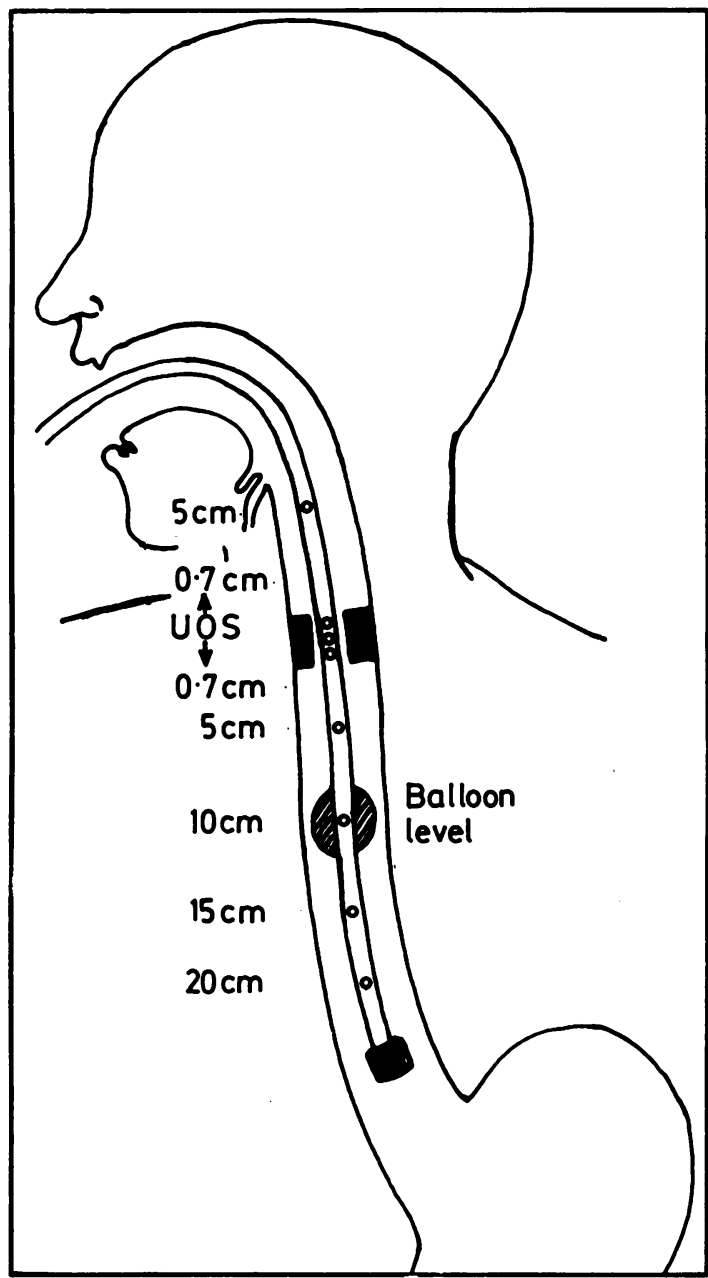

Fig. 1 The recording tube in situ and the position of the pressure recording sites and balloon relative to the upper oesophageal sphincter (UOS).

aged $20-28$ years) with no history of gastrointestinal disease were studied. Each gave informed consent for the study, the protocol of which had received approval by The London Hospital Ethics Committee.

\section{APPARATUS}

The multilumen oesophageal manometric tubes used for the study (Fig. 1) were constructed from triple lumen polyvinyl chloride (PVC) capillary tubing (internal diameter (ID) $0.5 \mathrm{~mm}$, external diameter (ED $1.5 \mathrm{~mm}$, side hole diameter $0.5 \mathrm{~mm}$, Dural Plastics, Australia) bonded around a central PVC tube (ID $1.0 \mathrm{~mm}$, ED $1.6 \mathrm{~mm}$ Portex, Hythe, Kent, England) and with a latex balloon constructed from a
$5 \mathrm{~cm}$ length of condom attached $15 \mathrm{~cm}$ from its tip. Three ports $0.7 \mathrm{~cm}$ apart were sited at the proximal end of the tube to ensure optimal detection of the upper sphincter, ${ }^{12}$ while five others sited at $5 \mathrm{~cm}$ intervals above and below the balloon, enabled detection of oesophageal responses to distension.

All tubes were continuously perfused at a rate of $0.3 \mathrm{ml} / \mathrm{min}$ using a standard Arndorfer type pneumohydraulic infusion system. Transmitted pressure changes were detected proximally using attached strain gauge transducers (Gaeltec, S8b, Skye, Scotland) the outputs of which were recorded on an eight channel chart recorder (Watanabe Linear Corder Mark VII, Tokyo, Japan), run at a paper speed of $100 \mathrm{~mm} / \mathrm{min}$ to provide a permanent graphic record. Because of the magnitude of the sphincter response, the calibration of the three sphincter channels was adjusted until their amplitudes were half those of the oesophageal body channels.

\section{MEASUREMENT OF BALLOON DIAMETER}

To provide an estimate of oesophageal diameter at each inflation volume, the diameter of the balloon was measured using calipers, both directly on a laboratory bench, and in three subjects using fluoroscopy during oesophageal distension. Any possible magnification effects of fluoroscopy on balloon diameter were corrected for by comparison with a radioopaque segment of known length attached to the tube.

\section{STUDY PROTOCOLS}

After a standard manometry study had been carried out on each volunteer to exclude oesophageal motor abnormality and to identify the location of the upper sphincter, the motor responses of the sphincter and proximal oesophagus to six predetermined balloon volumes $1,2,4,6,8$, and $10 \mathrm{ml}$ ), were recorded for three minutes at each inflation. Each inflation was achieved by injecting a known volume of tap water into the balloon channel of the tube and was separated by a control period of three minutes, during which the balloon remained deflated. The order in which the six inflations were performed was randomised for each individual. Because the pressure recorded within the sphincter is radially asymmetrical, ${ }^{29}$ the sphincter ports on the tube were maintained posteriorly orientated by taping the tube to the side of the mouth throughout the study after the correct position had been achieved.

During each balloon inflation, subjects were asked to indicate the occurrence of any retrosternal discomfort and to report any other sensations.

ANALYSIS OF DATA

Resting sphincteric pressure was determined by 


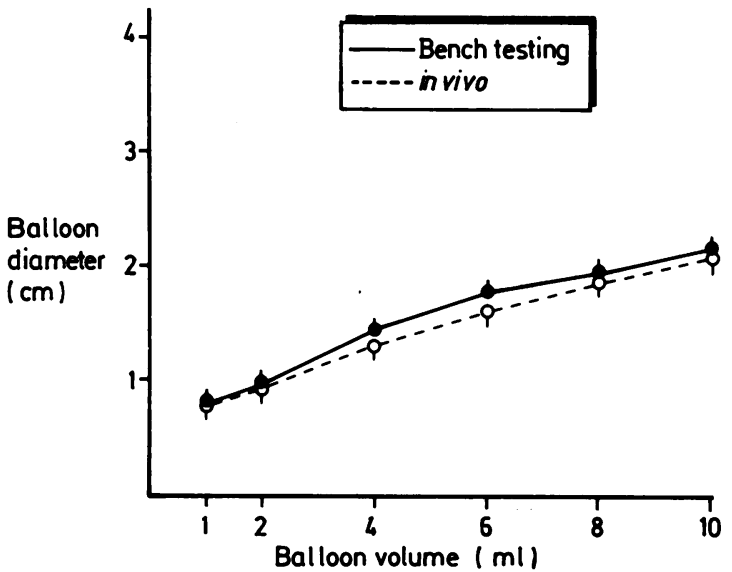

Fig. 2 Relationship between the balloon diameters measured directly on the laboratory bench with those measured at fluoroscopy. Values represent median and range of three studies.

measuring the difference between the values recorded from the sphincter ports when placed alongside the subjects neck and those recorded from the tube sited in the sphincter. Responses to distension were calculated by measuring the change from this baseline value to that of the new pressure, selecting for measurement whichever of the three ports showed the maximal response.

Secondary peristaltic responses to distension were determined at $5 \mathrm{~cm}$ proximal and at 5 and $10 \mathrm{~cm}$ distal to the balloon, by counting the number of nonswallow initiated waves occurring at each site during each inflation period and comparing this number with that found during the preceding control period.

In each subject the amplitude of each primary peristaltic wave was measured proximally and distally to the balloon, between and during each distension period, by direct measurement from the chart.

To determine response thresholds, the first distention volume which induced a significantly different response from the control data, was used. Because the data did not always appear to be normally distributed, Wilcoxon's rank sum test ${ }^{11}$ was used to test the likelihood that observed changes could have been due to chance.

\section{Results}

A total of 49 intraluminal oesophageal distensions were carried out in nine normal subjects. All

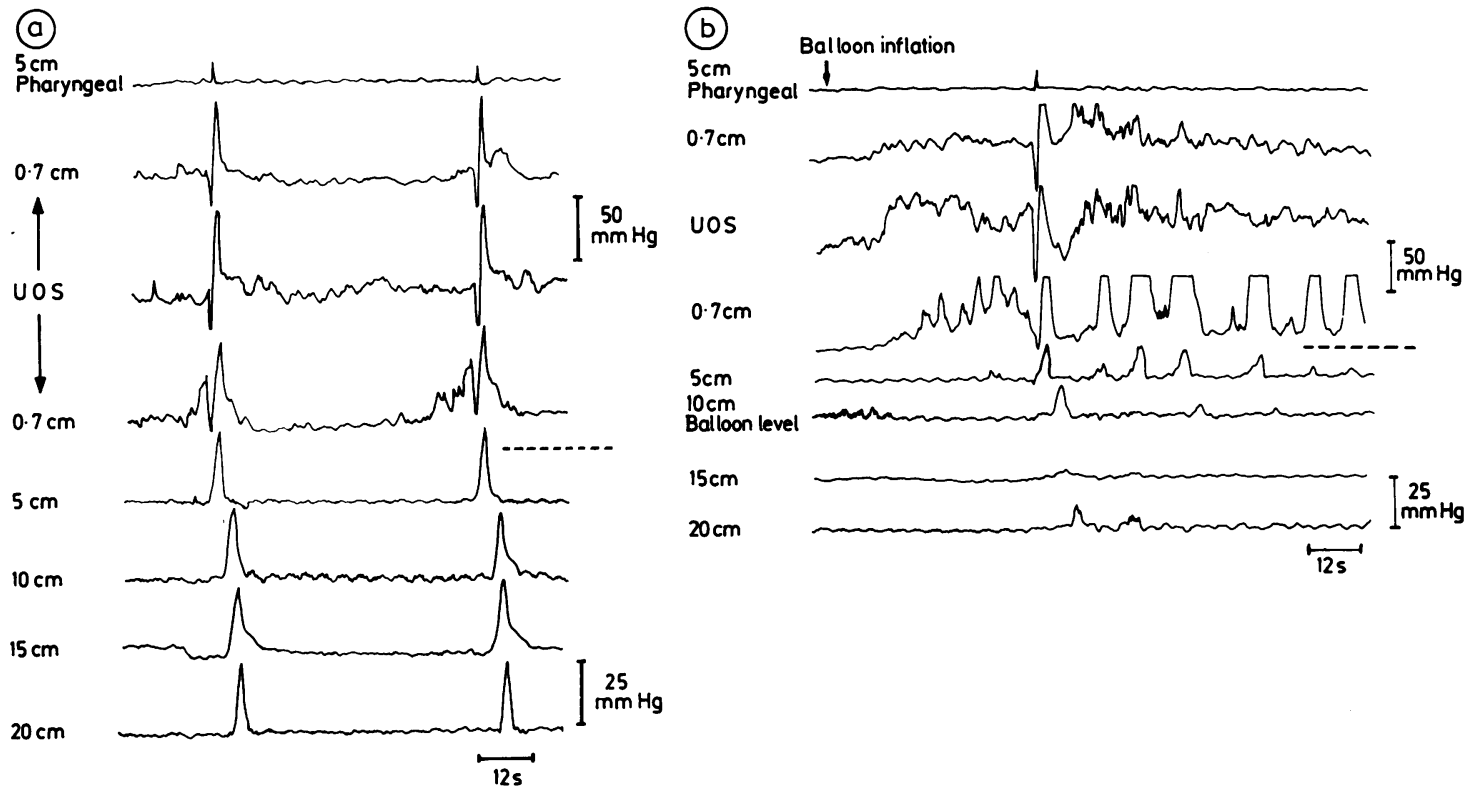

Fig. 3 (a) Normal manometric pattern of the upper oesophageal sphincter and oesophageal body during two swallows in a normal subject (balloon deflated). (b) The manometric responses of the cricopharyngeal sphincter and oesophageal body during $(6 \mathrm{ml})$ distension, in one subject. Note the increase in pressure at the UOS ports. Proximal to the balloon the number of secondary contractile waves can be seen to increase. There is no coincident distal change in secondary activity but the amplitude of the primary peristaltic wave initiated by swallowing 50 seconds after balloon inflation, can be seen to be attenuated distally. 
reported retrosternal discomfort at $8 \mathrm{ml}$ inflation and five were unable to tolerate $10 \mathrm{ml}$.

BALLOON VOLUME DIAMETER STUDIES

A good relationship was found between changes in balloon diameter when measured in air and at fluoroscopy (Fig. 2), indicating that at the distension volumes used, no significant distortion of the balloon was produced by the oesophagus. Inflation volume was therefore used as an index of oesophageal diameter for the remaining studies.

\section{UPPER SPHINCTER RESPONSES}

Basal sphincter pressures ranged between 25 to 50 mmHg (median value $30 \mathrm{mmHg}$ ). Oesophageal distension caused a rapid rise in sphincter pressure which was sustained for the duration of the distension period (Figs. 3a, 3b). The least distension required to initiate a sphincteric response in all subjects was $2 \mathrm{ml}$ $(1.0 \mathrm{~cm}$ diameter). The magnitude of rise in the sphincteric pressure above basal values increased progressively as the distension increased, rising from a median value of $42.5 \mathrm{mmHg}$ (range $37.5-55$ $\mathrm{mmHg}$ ) at $2 \mathrm{ml}$, to $95 \mathrm{mmHg}$ (range 50-110 $\mathrm{mmHg}$ ) at $10 \mathrm{ml}$ (Fig. 4). During inflation to $6 \mathrm{ml}$ and above, the most distal sphincter port also showed phasic contractions which often resembled the secondary peristaltic activity in the adjacent oesophagus. In some subjects this phasic change was so large that peak pressure values rose off-scale (Fig. 3b).

\section{OESOPHAGEAL BODY RESPONSES}

Secondary peristalsis

The proximal oesophagus responded to distension by

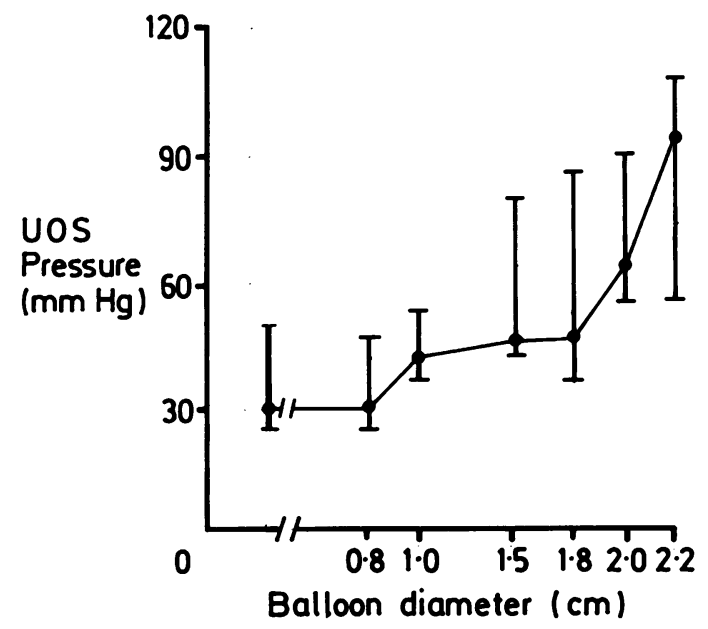

Fig. 4 Change in upper oesophageal sphincter pressure is shown with increase balloon distension. Value represent median and range for the nine subjects. an increase in the number of secondary contractile waves (Fig. 5); the threshold for this increase being 4 $\mathrm{ml}(0.5 \mathrm{~cm}$ diameter $)$. The number of these proximal non-swallow related contractions increased progressively as distension increased (Fig. 5). In contrast, the proportion of secondary waves detected distal to the balloon fell progressively, indicating a distension dependent inhibition of propagation across the balloon.

\section{Primary peristalsis}

The amplitude of swallow initiated pressure waves was measured, $5 \mathrm{~cm}$ proximal and 5 and $10 \mathrm{~cm}$ distal to the undistended balloon, and the average for each individual calculated. Proximally the median amplitude for the group was $28.5 \mathrm{mmHg}$ (range $23-42$ $\mathrm{mmHg}$ ) and distally $28.5 \mathrm{mmHg}$ (range 24-40 $\mathrm{mmHg}$ ). During distension the proximal amplitude was initially unchanged (median value $26.2 \mathrm{mmHg}$, range $23.63 \mathrm{mmH}, \mathrm{p}>0.05$ at $2 \mathrm{ml}$ ), but increased to $61.7 \mathrm{mmHg}(42-70 \mathrm{mmHg})$ at $10 \mathrm{ml}(\mathrm{p}<0.05)$, from a threshold of $6 \mathrm{ml}(1.8 \mathrm{~cm})$ (Fig. 6). Distal to the balloon the median amplitude fell progressively from a threshold response of $18.3 \mathrm{mmHg}$ (range 10-38.7 $\mathrm{mmHg}, \mathrm{p}<0.05)$ at $2 \mathrm{ml}$, to $7.5 \mathrm{mmHg}(6.2-12$ $\mathrm{mmHg}$ ) at $10 \mathrm{ml}$.

\section{Discussion}

These results show that the normal oesophagus responds to intraluminal distension with a stimula-

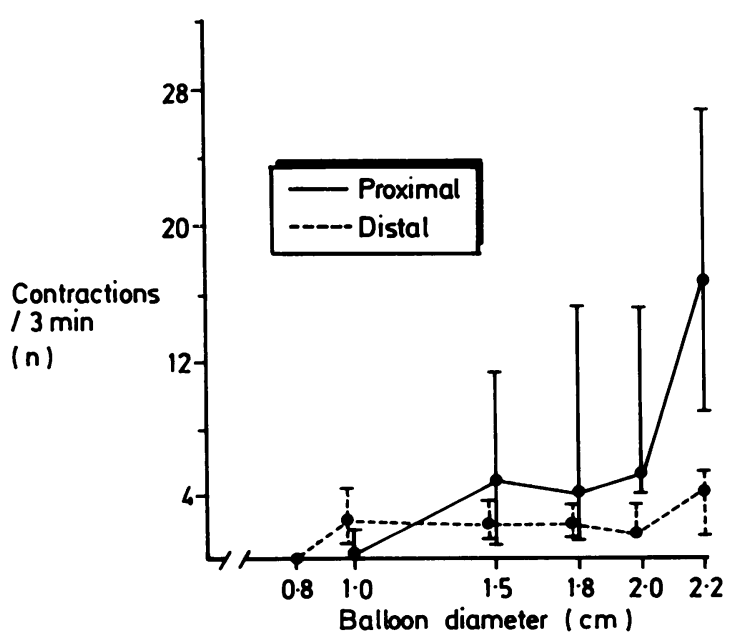

Fig. 5 Relationship between the number of secondary peristaltic contractions and balloon diameter, both proximal and distal to the balloon (values represent median [range] $n=9)$. As distension increases, the number of secondary contractions can be seen to increase proximally without a change distally. 


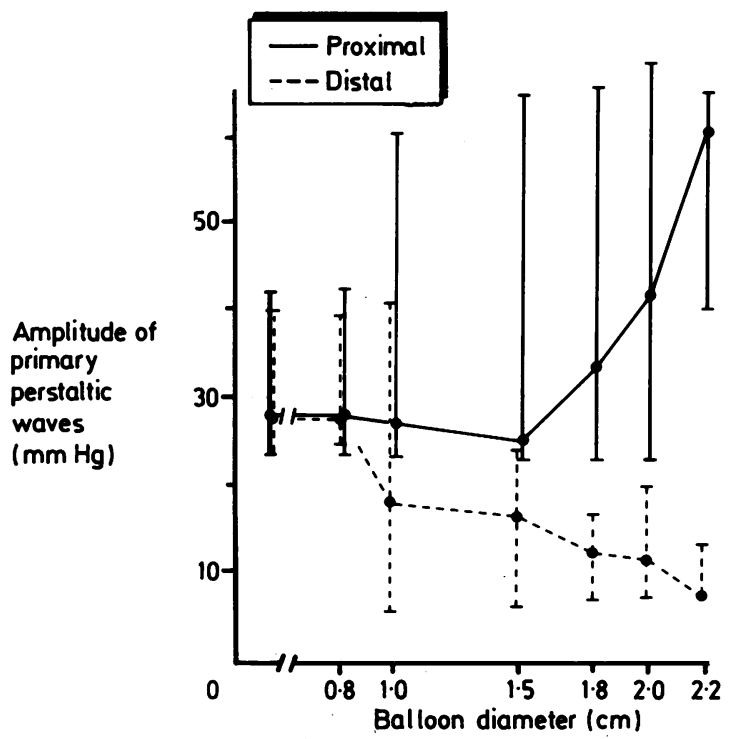

Fig. 6 Change in amplitude of primary peristaltic activity during distension (values represent median [range] $n=9$ ). Proximal to the balloon the amplitude increases progressively, but distally there is a progressive reduction.

tion dependent increase in sphincter pressure and in proximal peristaltic activity. The individual components of this response have been previously described by others, ${ }^{568}$ but our study is the first to show its graded nature and to describe the functional interrelationships between the sphincter and the oesophageal body.

The data on the upper sphincter differ from those of Siegel and Hendrix, ${ }^{7}$ who failed to show changes during distension. This difference, however, may be partly explained by differences in the design of the recording tubes used in the two experiments. Siegel and Hendrix ${ }^{7}$ used one sphincter recording port only whereas in this study three were used to enable continued detection of the maximal sphincter response even when the tube was slightly displaced.

Previous reports of distension induced peristalsis have also varied in their findings. Creamer and Schlegel, ${ }^{5}$ reported a pattern of response similar to ours, but Enzmann et $a l^{6}$ in contrast, noted the development of contractile activity below the distension site. This discrepancy may be because of the duration of distension used. Enzmann used a distension period of less than five seconds and thus probably included in the analysis post-distension responses such as the 'off response' of the peristaltic reflex seen both in vitro and in vivo. ${ }^{12} 13$

The phasic contractions recorded at the lowest sphincter port, during distension may represent the origin of secondary peristalsis in the sphincter.
Aboral displacement of the sphincter ports out of the sphincter cannot explain these results as the response was seen in channels which also showed the characteristic swallowing pattern of the sphincter. Furthermore, they were occasionally observed in all three sphincter ports.

The progressive modification of primary peristaltic activity with increasing distension, resulting in proximal enhancement and distal inhibition of contractile activity is a new observation although at extremes of distension distal peristaltic inhibition is known to occur. ${ }^{10}$

The close stimulus response relationship between the primary and secondary peristaltic responses suggests that a final common pathway is influenced by the distension, while the low thresholds for recruitment of all responses indicate that the responses probably represent part of the normal deglutitive process and are not just recruited for clearance of obstructing material.

While our data do not permit comment about the relative sensitivies of upper and lower oesophagus to distension, animal studies have reported ${ }^{14}$ that a gradient of responsiveness to distension exists, which declines in magnitude with distance from the upper sphincter, even after bilateral vagal blockade. This would suggest that the passage of intraluminal material is mediated by an intrinsic aboral gradient extending from the upper to the lower sphincter, which facilitates antegrade propulsion and prevents regurgitation or aspiration.

The in vitro data indicate, as might be expected, that when a highly compliant balloon is distended by indistensible liquid, its volume-diameter relationships are constant once the balloon is stretched to achieve a roughly spherical shape. The close similarity between these relationships in vivo and in vitro suggestion that oesophageal forces applied to the balloon were small because in vitro balloon pressures recorded over the range of inflation volumes used were small $(10-15 \mathrm{mmHg})$. If this is so then it suggests that oesophageal distension is accompanied by relaxation of the oesophagus not only below, but also at the site of the distension.

The relationship between degree of balloon distension and oesophageal response also deserves comment. All the measured responses showed greater changes as the balloon volume rose and quite marked changes occurred over a relative small change in diameter at the limit of distension. This pattern of response is probably the result of changes in circumference of the oesophagus which obviously increase proportionally more than diameter as distension increases.

The breakdown of the cooperative responses we have shown here is likely to have clinically important 
consequences. Although no specific studies have yet been conducted, it is of relevance to note that patients with symptoms of regurgitation and pulmonary disease have been reported to show upper sphincter hypotension, ${ }^{415}$ that patients with abnormal oesophageal peristalsis suffer increased pulmonary infections ${ }^{16}$ and, that patients with unexplained dysphagia may show abnormal secondary peristalsis despite normal primary peristaltic activity. ${ }^{10}$

It is possible, therefore, that the measurement of cricopharyngeal sphincter and oesophageal body responses to graded distension might prove to be a useful addition to routine manometry for the investigation of patients with unexplained dysphagia, regurgitation or pulmonary disease, and might uncover impairment of the oesophageal clearance process which would otherwise escape detection.

Dr Andreollo is a Research Fellow of the Brasilian National Council of Scientific and Technological Development (CNPq) and Unicamp (SP). Dr Thompson is a Wellcome Trust Senior Lecturer in Medicine. Dr Kendall was the WEG Knott Research Fellow of the British Digestive Foundation. We would like to thank Miss E Walker for her help in the performance of the studies, Dr D L Wingate (Gastrointestinal Science Research Unit) for his helpful advice and Ms Julie Rostron for typing the manuscript. A preliminary report of some of the data in this paper was presented to the British Society of Gastroenterology in April 1986.

\section{References}

1 Winship DH. Upper oesophageal sphincter: Does it care about reflux? Gastroenterology 1983; 85: 470-2.

2 Earlam R. Clinical tests of oesophageal function. London: Crosby-Lockwood-Staples, 1975.

3 Goyal RK, Cobb BW. Motility of the pharynx, esophagus and oesophageal sphincters. In: Leonard R
Johnson, ed. Physiology of the gastro-intestinal tract. New York: Raven Press, 1983; 1: 359-97.

4 Gerhardt DC, Castell DO, Winship DW, Shuck TJ. Esophageal dysfunction in oesophagopharyngeal regurgitation. Gastroenterology 1980; 80: 893-97.

5 Creamer B, Schegel J. Motor responses of the esophagus to distension. J Appl Physiol 1957; 10: 498-504.

6 Enzmann DR, Harell GS, Zboralske FF. Upper esophageal responses to intraluminal distension in man. Gastroenterology 1977; 72: 1292-8.

7 Siegel CI, Hendrix TR. Evidence for the central mediation of secondary peristalsis in the oesophagus. Bull John Hopkins Hosp 1961; 108: 297-307.

8 Gray JE, Lockard O, Shuck TJ, Winship DH. Responses of the upper esophageal sphincter and upper esophagus to intraluminal esophageal balloon distension. [Abstract]. Gastroenterology 1979; 76: A1143.

9 Gerhardt DC, Shuck TJ, Bordeaux RA, Winship DH. Human upper esophageal sphincter responses to volume, osmotic and acid stimuli. Gastroenterology 1978; 75: 268-74.

10 Kendall GPN, Thompson DG, Day SJ. Motor responses of the oesophagus to intraluminal distension. Gut 1987; 28: 272-9.

11 Siegel S. Non-parametric statistics for the behavioural sciences. Tokyo: McGraw Hill, 1956.

12 Christensen J, Lund GF. Esophageal responses to distension and electrical stimulation. J Clin Invest 1969; 48: 408-19.

13 Christensen J. Patterns and origin of some esophageal responses to stretch and electrical stimulation. Gastroenterology 1970; 59: 909-16.

14 Freiman JM, El-Sharkawy TY, Diamant NE. Effect of bilateral vago-sympathetic nerve blockade on response of the dog upper esophageal sphincter (UES) to intraesophageal distension and acid. Gastroenterology 1981; 81: 78-84.

15 Cargill G, Coutet JM, Vargas J. Gastro-oesophageal reflux in infants and children. Manometric analysis. Possible relation with chronic bronchopulmonary disease. [Abstract]. Gut 1983; 24: A357.

16 Hughes RL, French RA, Bytell DE, Craig TM, Moran JM. Aspiration and occult oesophageal disorders. Chest 1981; 80: 489-95. 